\title{
Improvement of energy absorption on magnesium alloy mixed carbon-nanotube and lead reinforcement materials in terms of high velocity impact
}

\author{
M.F. Abdullah ${ }^{1^{*}}$, S. Abdullah ${ }^{2}$, M.Z. Omar ${ }^{2}$, Z. Sajuri ${ }^{2}$, M.S. Risby ${ }^{1}$ \\ ${ }^{1}$ Department of Mechanical Engineering, Faculty of Engineering, Universiti Pertahanan Nasional Malaysia, Kem Sg. \\ Besi 57000 Kuala Lumpur, MALAYSIA. \\ ${ }^{2}$ Centre for Materials Engineering and Smart Manufacturing, Faculty of Engineering \& Built Environment, Universiti \\ Kebangsaan Malaysia, 43600 UKM Bangi, Selangor, MALAYSIA
}

Received 26 April 2018; accepted 6 August 2018, available online 30 October 2018

\begin{abstract}
This paper presents the fracture behaviour of magnesium alloy (AZ31B) with the reinforcement of carbon-nanotube (CNT) and lead subjected ballistic impact. Magnesium alloys are material that can absorb impact energy, however the absorption energy can be increased with the alloy reinforcement with nano-partial. This paper leads to two parts which are experiment and simulation of gas gun. The projectile used was a cone-nose type with diameter of $11 \mathrm{~mm}$ made by steel series 1006. The simulation used Cowper-Symonds model to see material behaviour with $25 \mathrm{~mm}$ thickness. The correlation of the experiment and simulations was evaluated to see the accuracy of simulations made. It was shown that the value of R2 was 0.9588 where simulation can be used to predict the ballistic impact on $600 \mathrm{~m} / \mathrm{s}$ velocity. From the simulation results, it was found that the depth of penetration for Magnesium alloy AZ31B reinforced with CNT and Pb showed good agreement findings. The depth of penetrations onto the simulation were obtained between 15 to $25 \mathrm{~mm}$. The added reinforcement materials provide a reduction in the depth of penetration of $40 \%$ compared to the original Magnesium alloy AZ31B. Thus, this type of magnesium alloy reinforced with $\mathrm{CNT}$ and $\mathrm{Pb}$ is suitable for ballistic resistant panel with weight saving determination on armoured vehicle.
\end{abstract}

Keywords: Ballistic; CNT; depth of penetration; Lead; Magnesium alloy AZ31B

\section{Introduction}

Recent technology development in automotive field requires lightweight material which has high strength. Exploration of new materials has high impact in the study of change in strain, especially when subjected to high velocity impact $[1,2]$. Changing strain at high velocity impact affects the material's energy absorption and prevents the occurrence of fracture failure $[3,4]$. The magnesium alloy is characterised as lightweight materials and has high energy absorption capability. Magnesium alloys can naturally withstand impacts effectively because of their unique combination of high tensile strength, low density, and superior shock absorbency which are 100 times greater than that of ordinary aluminium alloys [5]

Magnesium has a hexagonal close-packed structure (HCP). This structure affects the strength and ductility of materials because there are voids between the molecules $[6,7]$. Therefore, it is necessary to have a material that is able to fill these voids in order to prevent the structural collapse of the material. The most suitable materials to fill those voids are carbon nanotubes (CNTs). CNTs have unique characteristics that can generate strong materials with enhanced energy absorption properties, and many researchers have acknowledged that CNTs can improve the strength of materials [8,9]. CNT materials are produced from nano-technology for the purpose of filling the voids in structures and producing van der Waals bonds within them [10]. In addition, lead $(\mathrm{Pb})$ materials are also being used extensively to increase the absorption of energy as well as to enhance the ductility of materials. Since an increase in the ductility of a material is directly proportional to the elasticity of the material, an increase in the lead content can have an effect on the enhancement of the ductility of AZ31B [11].

Magnesium alloy can be good as ballistic resistance, but it must improve the material properties of magnesium alloy in terms of high velocity impact. This study determined the effects of energy absorption on the material AZ31B with reinforcement of $\mathrm{Pb}$ and $\mathrm{CNT}$ under high velocity impact. This study focused on simulation lead to observe the material behaviour in terms of energy absorption. It showed that reinforcement material improved the material properties of lightweight material in term of ballistic impact resistance.

\section{Methodology}

The methodology used for this study is shown in the flow diagram in Fig. 1. The sample was first prepared to 
enhance the determination of ballistic resistance of magnesium alloys with the combination composition of $\mathrm{CNT}$ and $\mathrm{Pb}$.

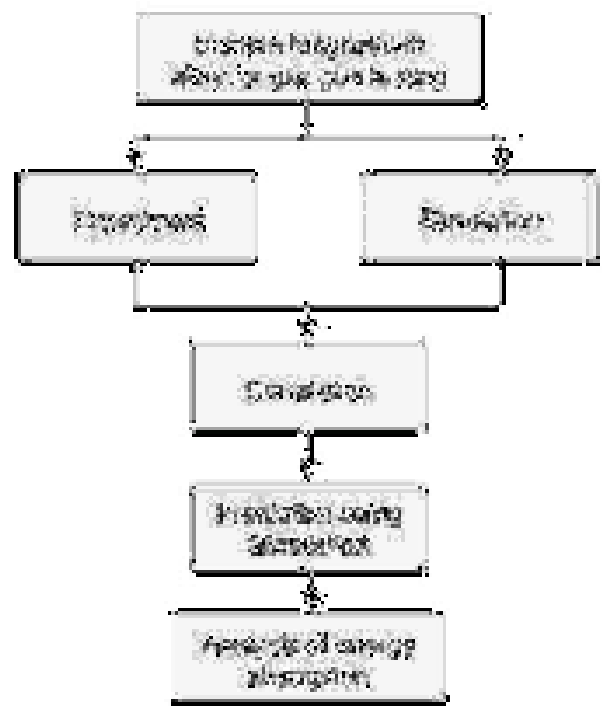

Fig. 1 Flow diagram of the methodology applied in the present work

\subsection{Simulation work}

A specific simulation software package was used to develop a three-dimensional (3D) model for the ballistic tests. The 3D model shows the effect of ballistic impact on the AZ31B plate. Finite element analysis was used to accommodate the Cowper-Symonds (CS) material model. The CS material model was used because it considers the damage evolution in the fracture and the thermal sorting effect in the material behaviour. This model is commonly used for impact simulation [12]. The CS model is represented by the following eq. (1):

$$
\sigma_{y}=\sigma_{0}\left[1+\left(\frac{\dot{\varepsilon}}{C}\right)^{\frac{1}{p}}\right]
$$

where $C$ and $p$ are the Cowper-Symonds coefficients, $\varepsilon$ is the strain-rate, $\sigma_{y}$ is the dynamic stress or strength and $\sigma_{0}$ is the quasi-static stress or strength. The coefficients obtained for Eq. 1 are presented in Tables 1 , along with the strain rate range of applicability and the mean squared value, $R^{2}$ for the tested materials. CS parameters for steel 1006 was referred to previous study [12] while the CS parameters for the magnesium alloy $\mathrm{AZ31B}$ and $\mathrm{AZ31B}+\mathrm{Pb}+\mathrm{CNT}$ were obtained from experimental work which involved the tensile test and split-Hopkinson pressure bar test.

Fig. 2 shows the simulation model set up for gas gun and the projectile used was conic nose steel 1006 projectile with a diameter of $11 \mathrm{~mm}$. The velocity performed was $143.44 \mathrm{~m} / \mathrm{s}$ and $286.88 \mathrm{~m} / \mathrm{s}$ because of the machine capability. Therefore, this simulation was predicted on energy equivalent method based on previous study [10] to determine the initial velocity required for this projectile and the initial velocity obtained was 600 $\mathrm{m} / \mathrm{s}$.

Table 1. Material Properties and Cowper-Symonds model parameters [12]

\begin{tabular}{cccc}
\hline $\begin{array}{c}\text { Material } \\
\text { Properties }\end{array}$ & Steel 1006 & AZ31B & $\begin{array}{c}\text { AZ31B } \\
+\mathrm{Pb} \\
+\mathrm{CNT}\end{array}$ \\
\hline $\begin{array}{c}\text { Density, } \rho \\
\left(\mathrm{kg} / \mathrm{m}^{3}\right)\end{array}$ & 7872 & 1770 & 1770 \\
$\begin{array}{c}\text { Young's } \\
\text { Modulus, } E \\
\quad(\mathrm{GPa})\end{array}$ & 206 & 45 & 45 \\
$\begin{array}{c}\text { Yield Strength, } \\
\sigma(\mathrm{MPa})\end{array}$ & 165 & 220 & 220 \\
$\begin{array}{c}\text { Strain rate } \\
\text { constant, } C \\
\text { Strain rate } \\
\text { exponent, } q\end{array}$ & 80 & 7124.56 & 3574.73 \\
mean squared \\
value, $R^{2}$
\end{tabular}

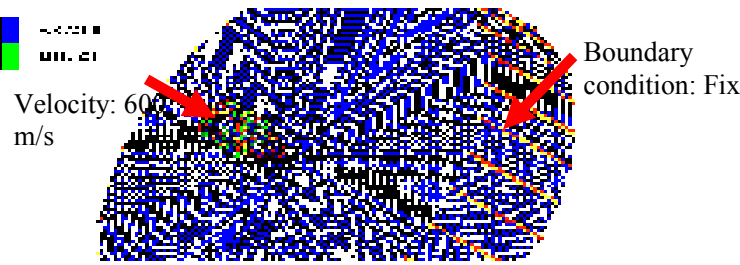

Fig. 2 Geometric model and boundary condition used for the simulation gas gun

\subsection{Experimental work}

Fig. 3 shows the gas gun system used. Helium gas was flowed onto the pressure tank to give pressure to push the bullet. This pressure can be adjusted at the control panel to play a role in the velocity of the bullet. The speed of bullet was measured using velocity gauge in front of the barrel. Fig. 4 shows the shape and size of the bullet used. The bullet used was a steel 1006 series and 10.68 grams of weight. The barrel of gas gun system used was about 3.0 metres. The surface of bullet must be finished using fine sandpaper on the 800 and 1200 surface roughness level [4]. This was to prevent internal barrel surface scratches that can cause uneven pressure to the bullet in the barrel. It would give the bullet not routed right to the target sample, on the other hand the bullet deflected to other directions. Based on the limitation of equipment, the speed of this experiment was at 143.44 $\mathrm{m} / \mathrm{s}$ and $286.88 \mathrm{~m} / \mathrm{s}$. These speed were obtained based on the measure gauge velocity in front of the barrel. This experiment was carried out on a sample AZ31B $+\%$ CNT $+\% \mathrm{~Pb}$. Experiment is important in selecting materials that have high ballistic resistance, with a sample size of $100 \mathrm{~mm}(L), 100 \mathrm{~mm}(W)$ and $25 \mathrm{~mm}(t)$ as shown in Fig. 5 . The depth of penetration, which is the bullet entering the sample was taken into account to see related ballistic resistance. 


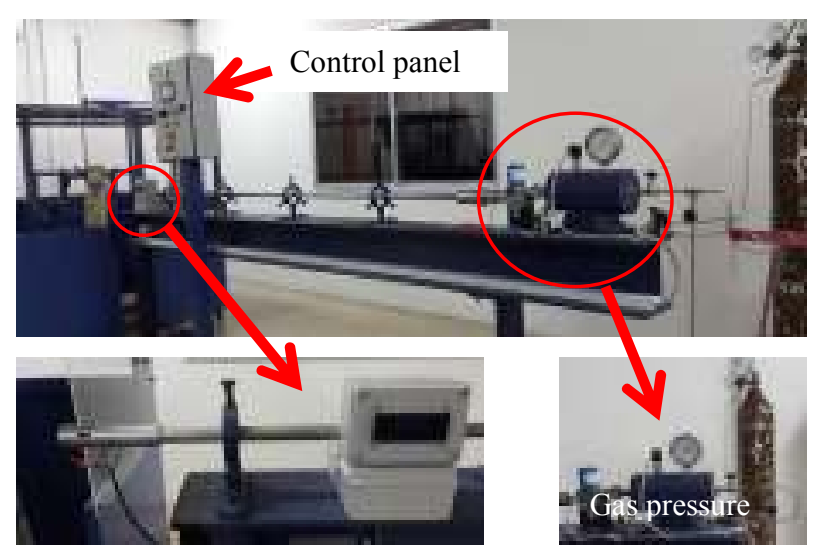

Fig. 3 Gas gun system for high velocity impact

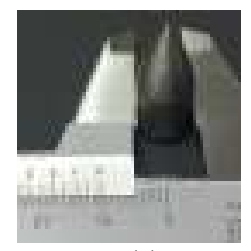

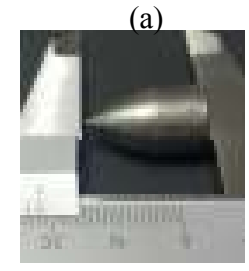

(b)

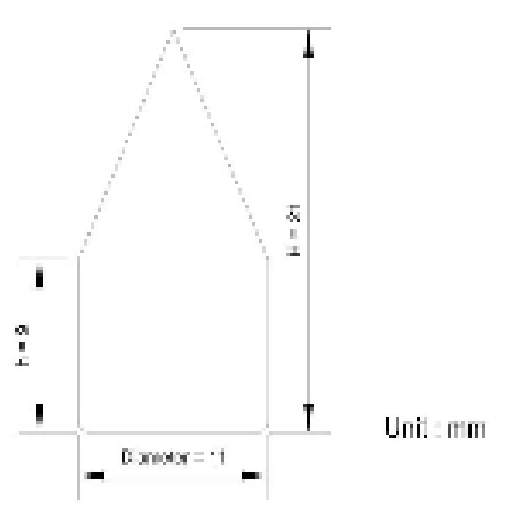

(c)
Fig. 4 Dimension bullet type steel series 1006; (a) the external Diameter, (b) the overall length, (c) Geometry bullet.

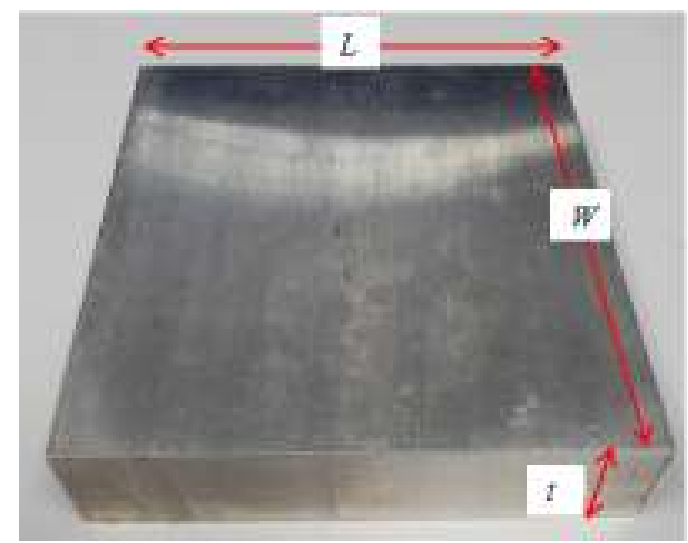

Fig. 5 Sample size for gas gun experiments

\section{Results and Discussion}

Analysis of the gas gun using velocity impact at $143.44 \mathrm{~m} / \mathrm{s}$ and $286.88 \mathrm{~m} / \mathrm{s}$ obtained from measurement of the velocity gauge system. The simulation and experiment analysed the correlation to get an accuracy of the two methods used. Figure 6 shows the comparison between the simulation and experiment results using a sample AZ31B with CNT and $\mathrm{Pb}$ at $143.44 \mathrm{~m} / \mathrm{s}$ velocity. The comparison was made, based on the depth of penetration and diameter penetration on the sample plate. Figure 7 shows the comparison between the simulation and experiment results using a sample AZ31B with CNT and $\mathrm{Pb}$ at $286.88 \mathrm{~m} / \mathrm{s}$ velocity. The comparison was also based on the depth of penetration and diameter penetration on the sample plate. On the other side of the bullet shows the equivalence between simulation and experiment.

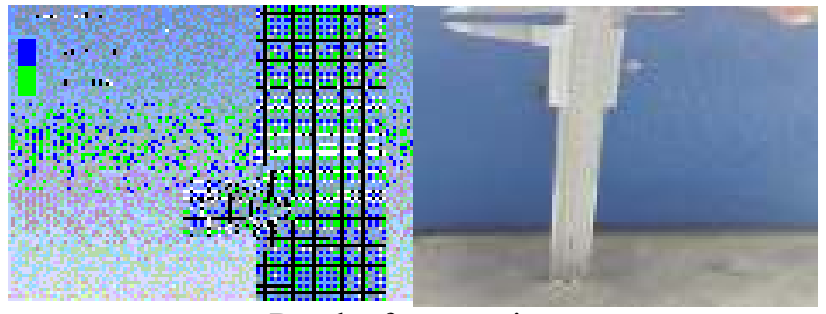

Depth of penetration

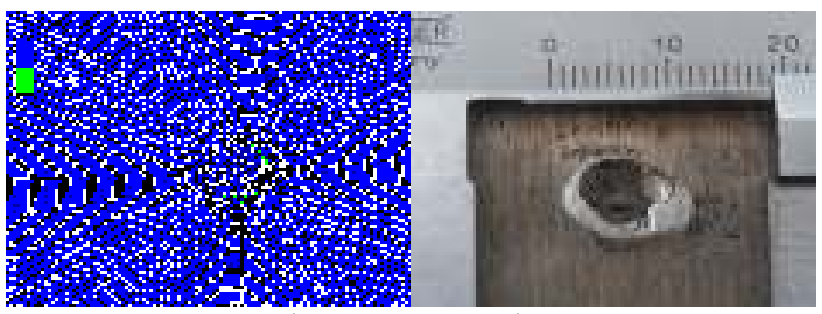

Diameter penetration

(a)

(b)

Fig. 6 Comparison depth of penetration and diameter for mixture AZ31B with CNT and Pb at velocity $143.44 \mathrm{~m} / \mathrm{s}$ (a) simulation, (b) experiment

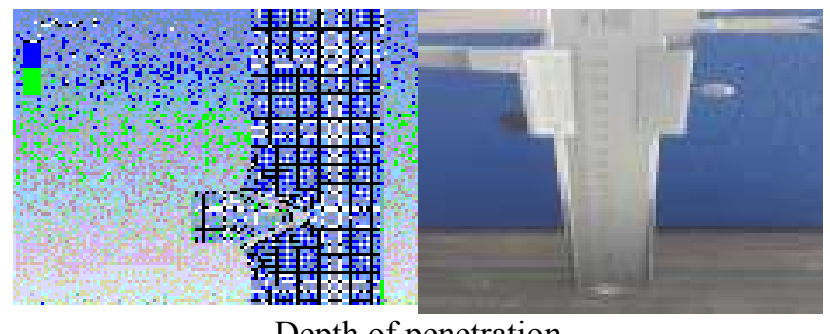

Depth of penetration

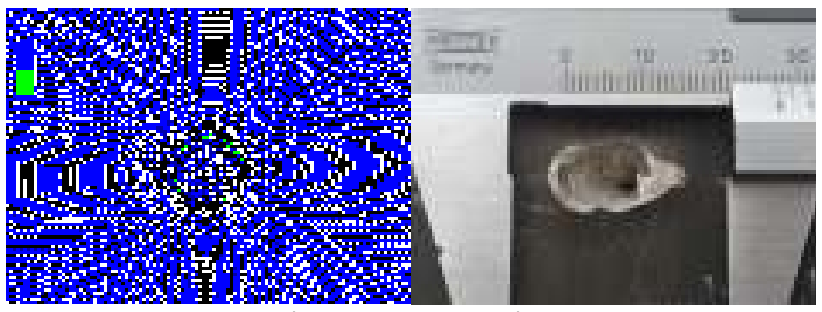

(a)

(b)

Fig. 7 Comparison depth of penetration and diameter for mixture AZ31B with CNT and $\mathrm{Pb}$ at velocity $286.88 \mathrm{~m} / \mathrm{s}$ (a) simulation, (b) experiment

Table 2 shows the data simulation and experiment on a sample of AZ31B with CNT and $\mathrm{Pb}$ applied at a different velocity. These data reflect a similar trend and it was a valuation of the correlation between experiment and simulation impact. Figure 8 shows the correlation graph of experiment and simulation on the gun gas impact. This correlation is related to the depth of 
penetration and diameter penetration. It was measured on the plate surface at $143.44 \mathrm{~m} / \mathrm{s}$ and $286.88 \mathrm{~m} / \mathrm{s}$ velocity. It was found, the correlation of $R^{2}$ was 0.9588 which is close to 1.000 (idea condition). This valuation in excess $85 \%$ of equivalents, which can be accepted in the statistical method [13-16]. Thus, the simulation can be done to estimate for each sample gas gun impact imposed at a higher velocity. The next velocity used to simulate was at $600 \mathrm{~m} / \mathrm{s}$ velocity which accounted equivalent to kinetic energy from the bullet type $5.56 \mathrm{~mm}$ NATO FMJ which is level 3 NIJ.

Table 2. Comparison depth of penetration and diameter at difference velocity

\begin{tabular}{lllll}
\hline & \multicolumn{2}{l}{$\begin{array}{l}\text { Depth of } \\
\text { penetration }(\mathrm{mm})\end{array}$} & \multicolumn{2}{l}{ Diameter $(\mathrm{mm})$} \\
\cline { 2 - 5 } & Sim. & Exp. & Sim. & Exp. \\
\hline $\begin{array}{l}\text { Velocity } \\
143.44(\mathrm{~m} / \mathrm{s})\end{array}$ & 5.91 & 6.30 & 7.50 & 8.00 \\
$\begin{array}{l}\text { Velocity } \\
286.88(\mathrm{~m} / \mathrm{s})\end{array}$ & 9.47 & 7.60 & 12.00 & 11.50 \\
\hline
\end{tabular}

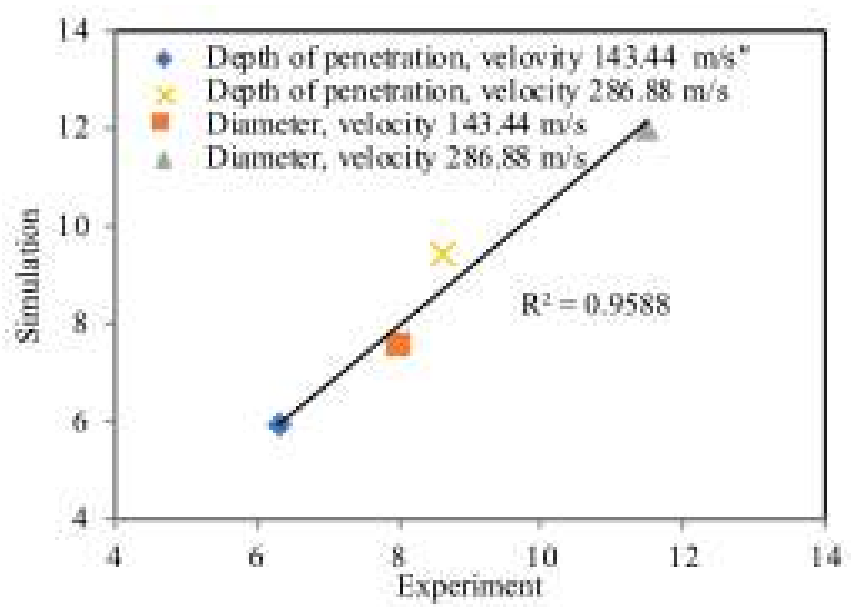

Fig. 8 Correlation on simulation and experiment for gas gun response

Figure 9 shows stress distribution patterns of each plate at time between $6 \mu$ s to $115 \mu$ s at initial projectile velocity of $600 \mathrm{~m} / \mathrm{s}$. Based on the simulation observation, the concentration of stress for each time was around the tip of projectile. The projectile retained its shape when penetrating the plate and the tip of the projectile was progressively deformed at the same time as the material in the panel was displaced and a hole was formed. The maximum stress of AZ31B was $1300 \mathrm{MPa}$ and AZ31B + $\mathrm{Pb}+\mathrm{CNT}$ was $537 \mathrm{MPa}$. It showed that the new combination of AZ31B with lead and CNT reduced the stress failure. The deformation occurred on the projectile nose during penetration has led to an immense heat generation and the material of the panel locally melted and lost all mechanical strength

Figure 10 shows the energy absorption response through depth of penetration of each plate. Figure 11 (a) shows the energy $(\mathrm{J})$ was absorbed through on magnesium alloys $\mathrm{AZ31B}$ and $\mathrm{AZ31B}+\mathrm{Pb}+\mathrm{CNT}$. It can be seen that the resulting graph of response shows the energy absorption of the magnesium alloys is uniform at $50 \mu \mathrm{s}$ for $\mathrm{AZ31B}+\mathrm{Pb}+\mathrm{CNT}$ and at $80 \mu \mathrm{s}$ for AZ31B. Figure 11 (b) shows the velocity $(\mathrm{m} / \mathrm{s})$ was decreased through the plates. From the analysis, the AZ31B plate was totally penetrated but the behaviour of material itself can still support the energy from projectile to stop it. The $\mathrm{AZ31B}+\mathrm{Pb}+\mathrm{CNT}$ can support the projectile with 15.06 $\mathrm{mm}$ penetration. It seems that the depth of penetration for $\mathrm{AZ3} 1 \mathrm{~B}+\mathrm{Pb}+\mathrm{CNT}$ was reduced about $40 \%$ compared to the original material.

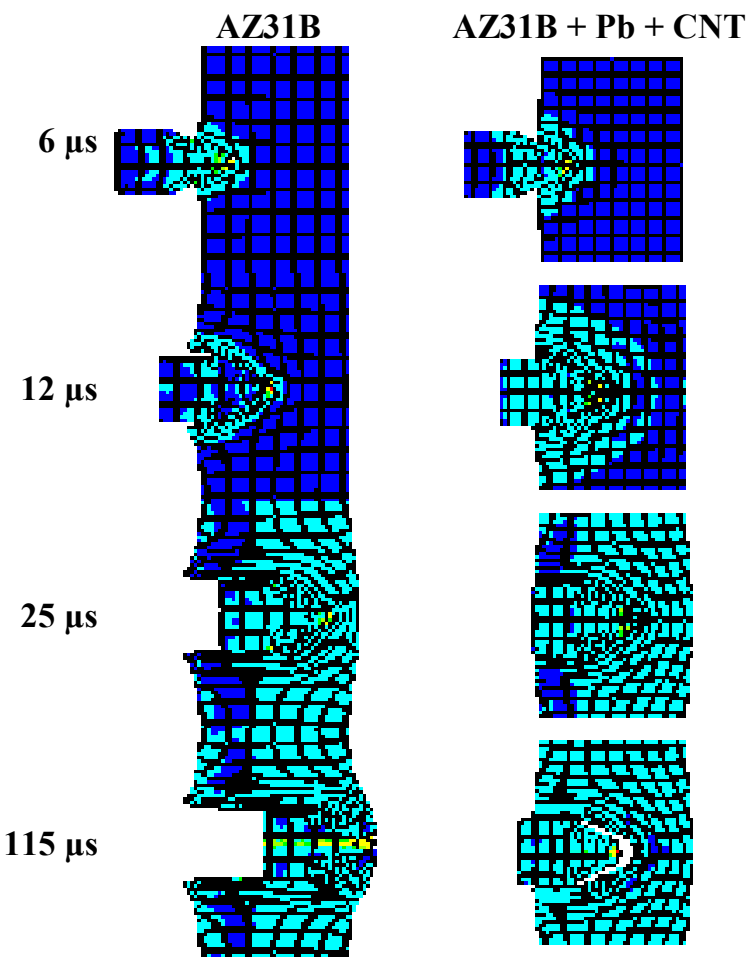

Fig. 9 Stress deformation patterns of each plate at time between $6 \mu$ s to $115 \mu$ s at initial projectile velocity of 600 $\mathrm{m} / \mathrm{s}$

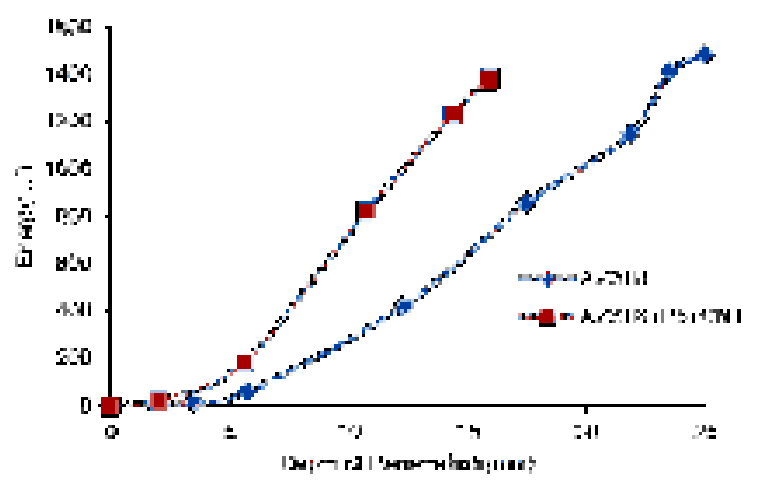

Fig. 10 Energy absorption response through depth of penetration 


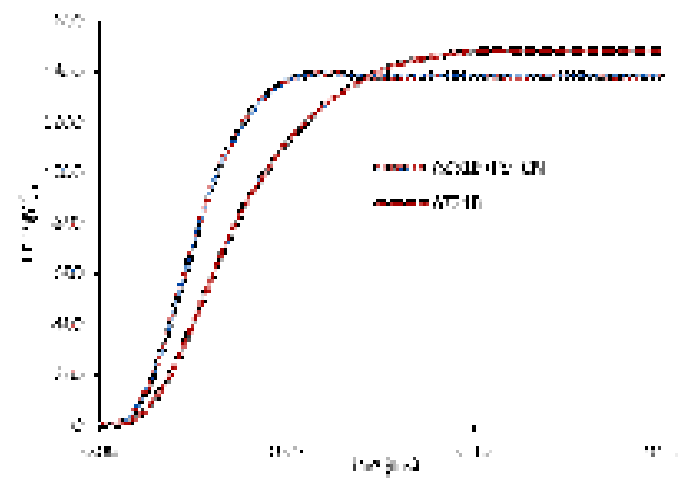

(a)

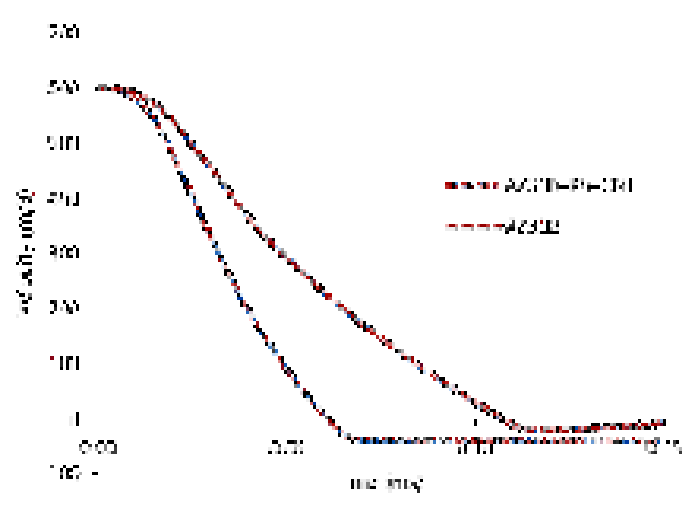

(b)

Fig. 11 (a) Trend of energy absorption increase through plates, (b) Trend of velocity decrease through plates.

\section{Summary}

The fracture behaviour of magnesium alloy with reinforcement of $\mathrm{Pb}$ and $\mathrm{CNT}$ has reduced the depth of penetration up to $40 \%$ compared to the original material. Reinforcement material such as $\mathrm{Pb}$ and $\mathrm{CNT}$ has increased the capability of energy absorption of materials. Energy absorption is an important factor in controlling the depth of penetration. However, fracture failure has occurred because the energy applied was beyond the energy absorption. Thus, the use of magnesium alloy in ballistic applications is feasible, but several of its properties need to be improved. Furthermore, the addition of element in the original alloy composition has enhanced the durability characteristics and resulted in a difference in energy absorption.

\section{Acknowledgments}

The authors would like to express their gratitude to Ministry of Higher Education Malaysia via Universiti Kebangsaan Malaysia and Universiti Pertahanan National Malaysia (Research funding: LRGS/2013/UPNM$\mathrm{UKM} / \mathrm{DS} / 04$ ) for supporting this research

\section{References}

[1] Naik, N. K., C. H. Veerraju \& V. R. Kavala. Hybrid composites under high strain rate compressive loading. Mater Sci Eng A 498(1-2) 2008, pp. 87-99.

[2] Li, Z., Lambros. J. Determination of the dynamic response of brittle composites by the use of the split Hopkinson pressure bar. Composites Science and Technology 59 1999, pp. 1097-1107.

[3] Chen, Y., Tekumalla, S., Guo, Y. B., Shabadi, R., Shim, V. P. W., \& Gupta, M. The dynamic compressive response of a high-strength magnesium alloy and its nanocomposite. Materials Science and Engineering A, 702(April) 2017, pp. 65-72.

[4] Asgari, H., A. G. Odeshi, J. A. Szpunar, L. J. Zeng \& E. Olsson. Grain size dependence of dynamic mechanical behavior of AZ31B magnesium alloy sheet under compressive shock loading. Materials Characterization 106 2015, pp. 359-367.

[5] Jones, T.L., Richard, D.D., Matthew, S.B., William, A.G. Ballistic performance of magnesium alloy AZ31B. 23rd Int. Sym. on Ballistics. Tarragona, Spain. 2007, pp. 989-995.

[6] Jena, P.K. K. S. Kumar, V. R. Krishna, A.K. Singh and T. B. Bhat. Studies on the role of microstructure on performance of a high strength armour steel. Engineering Failure Analysis 15 2008, pp. 10881096

[7] Haryanti Samekto. Design Modifications of a Thin Wall Part from Aluminium to Magnesium. International Journal of Integrated Engineering (Issue on Mechanical, Materials and Manufacturing Engineering) 2(1) 2010, pp. 79-87

[8] Guo, P., Li, L., Liu, X., Ye, T., Cao, S., Xu, C., \& Li, S. Compressive deformation behavior and microstructure evolution of AM80 magnesium alloy under quasi-static and dynamic loading. International Journal of Impact Engineering, 109, 2017, pp. 112-120.

[9] Gupta, M. \& W. L. E. Wong. Magnesium-based nanocomposites: Lightweight materials of the future. Materials Characterization 105 2015, pp. 30-46.

[10]Li, L., Muránsky, O., Flores-Johnson, E. A., Kabra, S., Shen, L., \& Proust, G. Effects of strain rate on the microstructure evolution and mechanical response of magnesium alloy AZ31. Materials Science and Engineering A, 684(December 2016), 2017, pp. 3746.

[11] Srinivasan A, Pillai U.T.S and Pai B.C. Effect of Pb addition on ageing behavior of AZ91 Magnesium alloy. Material Science and Engineering A. (452453) 2007, pp. 87-92.

[12] Hernandez, C., Maranon, A., Ashcroft, I. A., and Casas-Rodriguez, J. P. A computational determination of the Cowper-Symonds parameters from a single Taylor test. Applied Mathematical Modelling 37 2013, pp. 4698-4708

[13] Verrana, G. O., Mendesb, R. P. K. \& Dalla Valentinaa, L. V. O. DOE applied to optimization of 
aluminum alloy die castings. Journal of materials processing technology 200 2008, pp. 120-125.

[14] Kadiri, H. E., Wang, L., Gulsoy, H. O., Suri, P., Park, S. J., Hammi, Y. \& German, R. M. Development of a ti-based alloy: Design and experiment. The Minerals, Metals \& Materials Society 2009, pp. 60 - 66.

[15] Kleibergen, F. \& Zhan, Z. Unexplained factors and their effects on second pass -squared's. Journal of Econometrics 189(1) 2015, pp. 101-116.
[16]Hanis Mohd Yusoff, Nuur Ul Hazwani, Norhafiefa Hassan, and Fatin Izwani. Comparison of Sol Gel and Dehydration Magnesium Oxide $(\mathrm{MgO})$ as a Catalyst in Michael Addition Reaction. International Journal of Integrated Engineering, 7(3) 2015, pp. 43-50 